\title{
Supportive and Palliative Care of Advanced Nonmalignant Lung Disease
}

\author{
Michael Kreuter Felix J.F. Herth \\ Department of Pneumology and Respiratory Critical Care Medicine, Thoraxklinik, University of Heidelberg, \\ Heidelberg, Germany
}

\section{Key Words}

Supportive care $\cdot$ Palliative therapy $\cdot$ Advanced lung disease $\cdot$ Dyspnea $\cdot$ Cough

\begin{abstract}
Supportive and palliative care is an interdisciplinary challenge with the aims of symptom relief and improvement of quality of life in end-stage patients. Main complaints of patients with advanced nonmalignant lung disease are depression and anxiety, dyspnea, pain, and coughing. The discomfort of many physicians, caregivers, and family members with discussions about end-of-life care is one obstacle for the timely initiation of palliative care and the uncertainty of the short-term prognosis in most advanced nonmalignant respiratory diseases. Early dialog about supportive care already at the onset of the patient's first symptoms and contemporaneous to life-prolonging therapy may overcome these barriers. Furthermore, continuing education for health professionals in palliative care ensures adequate palliative support. Here, we review insights into symptom control and palliative care in patients with advanced nonmalignant respiratory disease.

Copyright $\odot 2011$ S. Karger AG, Basel
\end{abstract}

\section{KARGER}

Fax +4161306 1234

E-Mail karger@karger.ch

www.karger.com
(C) 2011 S. Karger AG, Basel

0025-7931/11/0824-0307\$38.00/0

Accessible online at:

www.karger.com/res

\section{Introduction}

Supportive care in advanced nonmalignant lung disease aims to relieve suffering and provide support to patients and their families in order to improve the quality of life of these compromised patients; palliative therapy focuses on reducing symptoms and providing comfort to patients rather than treating the respiratory disease. Both terms, supportive and palliative care, are often used as synonyms, as they will be throughout this review. In some definitions, palliative therapy is characterized as a part of supportive care focusing on the management of disease-related symptoms and providing psychological, social, and spiritual assistance for the advanced patient. In these definitions, supportive care aims to support the patient and his or her family, to increase treatment benefits, and to alleviate the disease's effects. This care should

Previous articles in this series: 1. Boehler A, Herth FJF: Palliation in lung diseases - facing the challenge and new hope: introduction. Respiration 2011;82:109-110. 2. Gompelmann D, Eberhardt R, Herth FJF: Advanced malignant lung disease: what the specialist can offer. Respiration 2011;82:111-123. 
be initiated at the onset of the patient's first symptoms and should accompany the patient from diagnosis, continuing during treatment, until death and into bereavement and is usually concomitant to curative and life-prolonging intended care as recently summarized by the ATS end-of-life care task force [1]. Moreover, it should especially be available to all patients near the end of life. Specific goals for end-stage disease patients are relief from physical and emotional distress and consideration of emotional support for patients and their families. Patients are considered to be in the terminal stage of their respiratory disease if, according to the ATS, severe chronic lung disease is documented by disabling dyspnea at rest resulting in decreased physical capacity, fatigue, and cough, by progression of their underlying lung disease documented by increasing emergency department or physician home visits or hospitalizations, and by severe respiratory or ventilatory failure. Further criteria might be right heart failure due to the respiratory disease, progressive pulmonary cachexia, and resting tachycardia [1].

\section{Quality of Life and Psychological and Spiritual Distress}

A chronic, progressive, and life-threatening disease usually raises questions regarding existence, the meaning of life, regret, and destiny [1]. Spiritual succor and help with these questions is a mainstay of palliative care. Here, the physicians' role includes support, catalysis, and facilitation - more treating feelings than treating physical complaints [2]. A multidisciplinary team of physicians, caregivers, social workers, and religious/spiritual advisors increases the likelihood that patients and their families get relief in this spiritual discomfort.

During the course of their respiratory disease, most patients suffer from psychological distress and they are at a substantially higher risk for depression and anxiety than healthy persons. Most symptoms discussed below are associated with psychological and spiritual distress: as a consequence and as a cause in a vicious circle decreasing the patients' quality of life. Therapeutically, control of complaints has to be achieved and depression and anxiety should be treated including possible pharmacotherapy. Antidepressive medication includes methylphenidate, serotonin selective reuptake inhibitors, and tricyclic antidepressants, while in treatment of anxiety benzodiazepines and buspirone should be considered. Moreover, nonpharmacological interventions like cognitive-behavioral approaches have a high value [1].

\section{Dyspnea}

Dyspnea is the term generally applied to sensations experienced by individuals who complain of unpleasant or uncomfortable respiratory sensations. Many definitions of dyspnea have been offered, including: 'difficult, labored, uncomfortable breathing' [3], an 'awareness of respiratory distress' [4], 'the sensation of feeling breathless or experiencing air hunger' [5], and 'an uncomfortable sensation of breathing' [6]. These definitions have sometimes mixed the true symptom (what patients say they are feeling) with physical signs (what the physician observes about the patient, e.g. 'exhibits labored breathing'). In the final analysis, a symptom can only be described by the person who experiences it. In this context, recent investigations of the perception of breathlessness suggest that there are multiple types of dyspnea [7].

Dyspnea is a term used to characterize a subjective experience of breathing discomfort that consists of qualitatively distinct sensations that vary in intensity. The experience derives from interactions among multiple physiological, psychological, social, and environmental factors and may induce secondary physiological and behavioral responses [7].

The sensation of dyspnea seems to originate with the activation of sensory systems involved with respiration. Sensory information is, in turn, relayed to higher brain centers where central processing of respiratory-related signals and contextual, cognitive, and behavioral influences shape the ultimate expression of the evoked sensation. The homeostatic systems involved in the regulation of respiration provide a framework for understanding the mechanisms of dyspnea [7].

There are various explanations of the pathophysiology of dyspnea. The respiratory control system functions to satisfy the metabolic requirements of the body. Signals from these chemoreceptors are transmitted back to brainstem respiratory centers that adjust breathing to maintain blood-gas and acid-base homeostasis. Also respiratory muscle abnormalities can lead to weakness or mechanical inefficiency of the respiratory muscles resulting in a mismatch between the central respiratory motor output and the achieved ventilation. Different diseases such as asthma and chronic obstructive pulmonary disease (COPD) which narrow airways and increase airway resistance and diseases of the lung parenchyma, including interstitial pneumonitis and pulmonary fibrosis, which decrease lung elastance, commonly cause dyspnea, pathophysiologically summarized as abnormal ventilatory 
impedance. Different breathing patterns and blood gas changes are also possible explanations [8].

It has been postulated that hypoxemia is a stimulus for dyspnea in its own right [9], though how it promotes breathlessness is unclear. One theory is that because hypoxemia acts as a respiratory stimulant the work of breathing is increased and this contributes to breathlessness. It is certain that not all hypoxemic patients are breathless and, of those that are, not all obtain benefit from oxygen therapy. Present evidence suggests that although oxygen supplementation prevents desaturation during exercise, it does not always relieve breathlessness. It may be that breathlessness during exercise in patients with COPD is related more to airflow limitations than to falling arterial oxygen saturation. There is no evidence that giving normoxemic patients short bursts of oxygen before exertion reduces breathlessness, though some hypoxic patients may be able to exercise longer at submaximal levels of effort [10]. Careful patient selection is necessary to identify those who will benefit from oxygen therapy. It is clear that a proportion of people receive very useful palliation from both short-burst and ambulatory oxygen but a larger number do not. It is important that those who do benefit can obtain it, and that those for whom it is ineffective are not burdened by its disadvantages [11].

The assessment of dyspnea is also a critical aspect of patient evaluation and management. While a sound history and physical examination remains the cornerstone of evaluation, the assessment of dyspnea is important. Possible assessment tools are the Saint George Respiratory Questionnaire (SGRQ) [12] or the Pulmonary Functional Status and Dyspnea Questionnaire [10].

All dyspnoeic patients require a broad range of treatment techniques. These are increasingly being recognized to be central to the management of all patients suffering from breathlessness, whatever its etiology, and for patients at every stage in their illness [13] for discussion of psychosocial therapies. Treatments need to be tailored to individuals and their concerns and priorities. End-stage lung diseases are often multisystem disorders and breathlessness may be one of a cluster of symptoms (sometimes the most troublesome), but for others it may be overshadowed by another symptom such as pain or immobility.

\section{Management of Dyspnea}

\section{Oxygen Therapy}

The recommendations regarding oxygen therapy [11] assume that it will be a part of comprehensive supportive care. Those who are dyspnoeic from COPD will often have had a long history and a slow descent into breathlessness. They may be accustomed to using oxygen during acute exacerbations of their illness. Lung cancer often occurs in patients who have COPD and who may have been using oxygen therapy for some time. In other patients with cancer and breathlessness the symptom may develop very rapidly. The patient often undergoes a rapid transition from feeling fit and healthy to being disabled by breathlessness. Oxygen is unlikely to be newly prescribed for a patient within hours of death (where pharmacological control of breathlessness is most appropriate), but it would also be unusual to remove it at this stage from a patient. Oxygen therapy in palliative care is more complex than the treatment of hypoxemia itself [8].

Most of the work carried out with regard to oxygen therapy has been in patients with COPD [11]. In many of the studies reported, the effect of oxygen on breathlessness or the patient's quality of life has not been considered. Usually the outcome measures have included more directly measurable parameters such as work capacity, exercise endurance, pulmonary function tests, and arterial blood gases [8].

It should be remembered that breathlessness is a symptom and the population of people who describe themselves as breathless is very heterogeneous, ranging from those who are breathless at rest to those who are troubled more intermittently and inconstantly. The evidence for the use of oxygen in those breathless at rest and upon exertion will thus be considered separately [8].

However, in contrast to patients with COPD undergoing long-term oxygen therapy, who have a prognosis of months to years, palliative care patients disabled by dyspnea may have an expected survival of days to weeks. Evidence of hypoxemia by pulse oximetry can give weight to the argument for the use of oxygen although dyspnea may be present and alleviated by oxygen therapy even when the patient is only mildly hypoxemic.

\section{Corticosteroids}

Corticosteroids are anti-inflammatory agents used as adjuncts in the management of asthma, COPD, and fibrotic lung disease and to palliate respiratory symptoms including breathlessness in end-of-life care [10]. Evidence to support the latter derives largely from clinical experience. The choice of corticosteroid seems to be determined by the individual clinician's preference. The benefits of dexamethasone, which is widely used in the palliative care setting, as compared with prednisolone include reduced mineralocorticoid effects, increased potency, and 
higher solubility. Disadvantages of all corticosteroids include adrenal insufficiency following abrupt withdrawal and a wide range of well-known adverse effects related to both mineralocorticoid and glucocorticoid actions. Close monitoring of the treatment outcome is essential, together with a willingness to discontinue the drug if it proves unhelpful [10].

\section{Respiratory Stimulant Drugs}

Theoretically, pharmacological stimulation of ventilation in some chronically hypoxemic patients with carbon dioxide retention could improve symptoms. Actually respiratory stimulant drugs are hardly ever used. They may have a role in a few patients in whom hypoxia or hypercapnia causes excessive daytime somnolence or nighttime sleep disturbance. Currently, interest focuses on mechanically rather than pharmacologically assisted ventilation [10].

\section{Benzodiazepines}

Benzodiazepines are respiratory sedative drugs which reduce respiratory drive and may reduce pulmonary ventilation [14]. It is also possible that the anxiolytic properties of these drugs are therapeutic in some breathless patients. Alternatively, drugs in this class may affect breathlessness through a direct effect on respiration or by causing relaxation of respiratory muscles or, perhaps more likely, through a combination of factors. In practice, the use of low-dose benzodiazepines in the form of a therapeutic trial may be cautiously recommended, particularly when anxiety is prominent and when breathlessness appears intractable. Unfortunately, there is very little scientific evidence upon which to base clinical decision making and none to inform the decision of whether a therapeutic trial of an opioid drug or a benzodiazepine or both may be appropriate [10].

\section{Opioids}

Opioid drugs have been used for centuries for a wide range of indications, including relief of dyspnea. Most palliative care physicians agree that low-dose systemic opioids have a place in the symptomatic management of breathlessness in patients with both malignant and nonmalignant lung disease. Opioids can cause respiratory depression, but it is important to remember that this risk varies between patients and appears to be related to a number of factors including the underlying pathophysiology, prior exposure to opioids, the route of administration, the rate of dose titration, and coexisting pathologies. In 1984 Walsh et al. [15] demonstrated no respiratory de-
Table 1. Opioid dosages at the initiation of therapy in opioid-naive adult patients with moderate-to-severe pain or dyspnea according to Lanken et al. [1]

\begin{tabular}{lclc}
\hline Agent & Intravenous & Oral & Duration \\
\hline Oxycodone, mg & n.a. & $5-10$ & $4-6 \mathrm{~h}$ \\
Methadone, mg & $2.5-10$ & $5-10$ & $4-12 \mathrm{~h}$ \\
Morphine, mg & $2-10$ & $5-10$ & $3-4 \mathrm{~h}$ \\
Hydromorphone, mg & $0.3-1.5$ & $2-4$ & $3-4 \mathrm{~h}$ \\
Fentanyl, $\mu \mathrm{g}$ & $50-100$ & n.a. & $0.5-1 \mathrm{~h}$ \\
\hline
\end{tabular}

n.a. $=$ Not applicable

pression, assessed by arterial blood gases, in most of a group of cancer patients taking more than $100 \mathrm{mg}$ of oral morphine per day for pain $[10,15]$.

In clinical practice in breathless patients previously naive to opioids, a therapeutic trial of low-dose oral opioids, e.g. $2.5 \mathrm{mg}$ of immediate release morphine sulfate every $4 \mathrm{~h}$, is often appropriate (table 1). The dose can be titrated upwards. There is debate about the choice of opioid dose for breathlessness in patients who are already receiving strong opioid drugs for pain [10]. Most advocate an increase in the dose, but the size of this dose increment should probably be decided on an individual patient basis.

Parenteral opioids (e.g. $2.5 \mathrm{mg}$ diamorphine as a subcutaneous bolus injection or $10 \mathrm{mg}$ diamorphine as a subcutaneous infusion over $24 \mathrm{~h}$ ) are used in patients in whom oral drug administration is no longer appropriate or possible. If opioids are used, the coprescription of appropriate laxative therapy is particularly important. An alternative to the parenteral route in terminally ill patients could also be the use of nebulized fentanyl [16].

There is no research investigating the possibility of using opioid drugs preemptively in patients who become breathless upon exertion but this strategy seems effective in some patients and may restore a sense of control.

When the cause is irreversible and death is imminent, the appropriate aim of care is relief of suffering. Induction of sedation under these circumstances may be achieved by means of slow intravenous titration of, for example, midazolam or and morphine.

\section{Cough and Expectoration}

Cough is a protective and defensive reflex in healthy individuals which has the function of clearing the airways of foreign material and of secretions and limiting 
the exposure to noxious stimuli; it is also influenced by psychological factors [17]. Life is impossible in the absence of these reflexes; however, perturbing cough is a common phenomenon with a prevalence of $9-33 \%$ in the general population [18].

Cough is mostly divided into acute and chronic cough - the latter defined as lasting more than 8 weeks. Additionally, it is subdivided into nonproductive and productive cough. Productive cough appears to be due to an increased stimulation of the physiological cough reflex by endobronchial material whilst nonproductive cough is mainly associated with a hypersensitive reflex and a trivial stimulation leads to an excessive response [19]. Cough can be an indicator of a serious pulmonary disease such as a malign tumor or lung fibrosis as well as nonpulmonary disorders such as gastroesophageal reflux disease. Furthermore, it can in itself disable the person socially and coughing can be associated with a couple of complications such as rib fractures, pneumothoraces, stress incontinence, and syncope.

Careful clinical workup of patients with chronic cough mostly identifies an underlying disease leading to specific and mostly effective treatment. Clinical evaluation of chronic cough includes a detailed history and a physical examination. Important issues are medication, smoking history, respiratory tract symptoms typically for pertussis, symptoms of asthma and gastroesophageal reflux disease, as well as symptoms of upper airway diseases such as postnasal drip or sinusitis. A chest radiograph and measurement of lung function are mandatory diagnostic procedures. Further examinations might include bronchial provocation testing, bronchoscopy, and a highresolution CT scan - several national and international guidelines are available on this topic [20-22]. Treatment depends on the underlying disease as multiple studies have shown that etiology-aimed therapy for cough is highly effective and the prescription of nonspecific antitussive medication ameliorates symptoms in most cases only temporarily.

Cough and Its Treatment in Advanced Lung Diseases

Cough may be a very distressing and disabling symptom in a number of advanced nonmalignant respiratory diseases including COPD, diffuse parenchymal lung disease, and bronchiectasis. In these patients, physical, psychological, and social domains are commonly affected: they frequently report musculoskeletal chest pains and sleep disturbance and this can aggravate or cause vomiting and dyspnea. Moreover, the psychological impact of chronic cough in the palliative patient includes a high prevalence of depressive symptoms and has a major impact on the quality of life of these patients $[21,23,24]$.

The first therapeutic approach in palliative care should be to treat reversible causes. With cough thought to originate from gastroesophageal reflux disease, proton pump inhibitors may be tried, and in supposed upper airway pathology, the use of topical corticosteroids should be considered [21]. Moreover, if possible, treatments directed at the underlying condition should be used. However, in most cases of advanced disease, these attempts are not successful. In cough due to irreversible causes, therapy with cough suppressants, which are intended to suppress the cough reflex regardless of the causative factor, might be necessary and appropriate. Cough suppressants include centrally acting drugs such as the opiates diamorphine, morphine, and codeine as the most effective antitussives, nonnarcotic synthetic morphine derivatives such as dextromethorphan, which has no sedative or analgesic qualities, and peripheral cough suppressants such as levodropropizine and moguisteine [25, 26]. However, data - especially in advanced and chronic diseases - are limited and conflicting. While previous studies have demonstrated an inhibitory effect on chronic cough in COPD for codeine and dextromethorphan [27], as well as for levodropropizine and moguisteine [28, 29], a more recent trial in COPD patients failed to prove effectiveness in reducing cough with a high dose of codeine $(60 \mathrm{mg})$ [30]. Still, in patients with severe chronic cough, low doses of sustained-release morphine (5-10 mg twice daily) may provide reasonable relief of cough but, unlike with pain, higher doses do not necessarily improve the effectiveness. In this context, Morice et al. [31] reported efficacy in about $40 \%$ of the patients and an improvement of quality of life with good treatment toleration by the patients. However, constipation was noted in $40 \%$ of patients and 25\% complained of drowsiness [31]. The use of oral corticosteroids may also provide relief of cough in some patients. For nonsmoking idiopathic pulmonary fibrosis (IPF) patients, for instance, Hope-Gill et al. [32] demonstrated that treatment with oral corticosteroids decreased cough severity and sensitivity to capsaicin and substance P. A study by Horton et al. [33] also suggests that thalidomide may be beneficial for chronic cough in IPF. Nebulized drugs with local anesthetic properties, such as lidocaine, have also been proven to provide relief from chronic cough [34]. Derived from the care of lung cancer patients, there are a number of further options that could be considered, however, with only marginal evidence and possible toxicities, such as baclofen, gabapentin, carbamazepine, or amitriptyline [35]. Cough sup- 
pressants should be used with caution in diseases usually associated with a significant production of mucus such as bronchiectasis or COPD as this could lead to the accumulation of mucus with an increased risk of lung infections or worsening of dyspnea [26]. However, in some of these conditions, an enhanced cough reflex has been described $[36,37]$ and, therefore, excessive cough in COPD patients may partially be related to an enhanced cough reflex with at least some mitigating effect by cough suppressant drugs in the advanced disease patient.

\section{Expectoration and Its Treatment in Advanced Lung}

Disease

In many patients with advanced lung disease, either increased mucus production, poor clearance, or mainly a combination of both leads to excessive mucus needing expectoration. As with cough, treatment of the underlying cause of expectoration is desirable; however, in most cases it is not feasible.

Mucolytic therapy in order to aid expectoration aims to prevent cysteine bridging between glycoprotein molecules, e.g. using acetylcysteine. However, conflicting data exist on this topic and there is reasonable debate as to whether these drugs are clinically effective [38]. The topical use of mucolytics instilled through the bronchoscope has been reported useful in patients with mucus plugging; however, this has never been investigated in a controlled study. Enzymatic degradation of DNA is an alternative strategy and has had proven efficacy in reducing sputum viscosity and the rate of exacerbations in patients with cystic fibrosis but not in COPD or other pulmonary diseases $[38,39]$.

Inhalative therapy, either in the form of nebulized solutions or as steam inhalation, with isotonic or hypertonic (3-7\%) saline promotes expectoration. While evidence for the use of isotonic saline is poor, treatment with hypertonic saline significantly improves lung function in cystic fibrosis [40]. To overcome the frequent clinical problem of bronchoconstriction in patients with reactive airways after inhalation with hypertonic saline, pretreatment with bronchodilators might be beneficial. The repeated application of bronchodilators, especially in the nebulized form, in patients with chronic obstructive lung disease also aids expectoration. Anticholinergics (e.g. hyoscine) may be particularly important in the end-stage patient, with the aim of suppressing secretions and subsequent cough. Furthermore, anticholinergic substances like atropine or glycopyrrolate given to terminally ill patients provide rapid relief from excess secretions $[38,41]$.
One of the most effective therapies of expectoration is physiotherapy. Autogenic drainage, specifically designed to aid expectoration, uses inspiration at increasing lung volumes to facilitate expectoration [42]. The use of a cough assist, which is a noninvasive therapy clearing secretions by applying positive pressures and then rapidly changing to negative pressures, or similar approaches also helps to remove secretions in patients, predominantly those with muscular or neurologic disorders, with an ineffective cough ability (peak cough flow $<270$ liters/m).

\section{Pain}

Pulmonary or chest pain is usually not an isolated clinical complaint; however, it may be the first manifestation or sign of deterioration of pulmonary disease. Anatomical structures in the respiratory system which can be affected by painful sensations are the chest wall, diaphragm, pleura, tracheobronchial tree, and vascular structures while the lung interstitium is relatively insensitive [43]. In advanced nonmalignant pulmonary diseases, chest pain is mainly caused by infection or inflammation and sometimes by trauma including surgery and pneumothorax. Typical examples are tracheobronchitis, pneumonia, pleuritis, pleurisy, empyema, and rib fractures. Moreover, in obstructive airway disease, patients sometimes complain of chest tightness or retrosternal pain sensations, which can be related to dynamic hyperinflation. Rare but clinically important examples are chest wall invasion by actinomyces infection or nerve compression by tuberculosis. However, cardiovascular pathologies like coronary heart disease, aortic aneurysm, pulmonary embolism, and pericarditis or other conditions like herpes zoster infection, thrombosis, or osteoporotic fracture, etc., have to be ruled out [44]. Besides, there are several further aspects of chest pain to be considered in patients suffering from advanced disease: thoracic pain also constrains respiration and may cause dyspnea and anxiety. The adequate relief of pain is therefore one of the essentials of supportive care in advanced disease. One of the most important aspects in the dying patient is a peaceful, painless death, which also helps alleviate the bereavement of the patients' relatives and friends. The clinical assessment of chest pain with regards to onset, severity, localization, character, time course, and exacerbating and relieving factors assists in making a diagnosis of the cause of pain and guiding its therapy as well as assessing the symptom in the context of a clinical problem [45]. 
Pain Management in Advanced Nonmalignant

Respiratory Disease

Treatment of pain is an important therapeutic aspect in palliative care and should be individualized according to the patients' desires with respect to the therapeutic effects like analgesia and anxiolysis as well as to side effects like unwanted sedation or nausea. Analgetic therapy should be chosen according to the pain category and intensity [45]. The preferred administration is orally, and in case of infeasibility alternatively transdermally, subcutaneously, rectally, or intravenously [45]. The WHO 3-step 'ladder' for pain relief is the treatment of choice in primarily nociceptive pain. This ladder recommends nonopioids like NSAIDs or paracetamol as the first choice and then, if necessary, ancillary mild opioids (e.g. codeine and tramadol) and as a subsequent step strong opioids (e.g. morphine, fentanyl and hydromorphone) until the patient is free of pain (table 1). In case of anxiety, adjuvant drugs are recommended. To maintain analgesia, drugs should be given in a fixed schedule rather than on demand [46]. In predominant neuropathic pain, opioids and anti-inflammatory drugs like NSAIDs or steroids might be helpful in cases of nerve pain associated with inflammation and edema. However, in the event of nerve damage, further adjuvant drugs like anticonvulsants or tricyclic antidepressants are needed [45]. Interventional treatment options like nerve blockades or intrathecal or epidural administration of neurolytic agents are an important addition to conservative treatment in cases of persistent neuropathic pain.

In patients with underlying respiratory disease, attention should be paid to specific pulmonary side effects of analgetic medication: NSAIDs may induce bronchospasm in susceptible patients. Also for morphine, bronchospastic reactions have been described [45]. However, the most important side effect of strong opioids to be considered is respiratory depression, which is dose related and is subject to a tolerance effect. A more welcomed effect of morphine is the finding described by Krajnik et al. [47] that it may lead to a decrease in bronchial inflammation and in sputum production as well as to decreased oxygen consumption in peripheral tissue.

\section{Hemoptysis}

Airway bleeding might occur in patients with endstage lung diseases such as tuberculosis or bronchiectasis. Its incidence in bronchiectasis patients, for example, was reported to be up to $40 \%$ of and is usually minor, with intermittent episodes of bright bleeding of small volume. Occasionally, massive hemoptysis may occur $(>200$ $\mathrm{ml} / 24 \mathrm{~h}$ ) [48]. Bleeding is often associated with an exacerbation of infection and microabscess formation in inflammatory lung disease. The importance of airway bleeding can be easily underestimated. When intervention is required, bronchoscopy is the technique of choice. For further details on bronchoscopic interventions for hemoptysis, we refer to another review in this series [49]. In some cases angiography with embolization of the affected vessel is necessary. A diligent search by an experienced radiologist may be required.

\section{Specific Benign Pulmonary Diseases}

\section{Chronic Obstructive Pulmonary Disease}

COPD is one of the leading causes of morbidity and mortality worldwide. Despite maximal therapy, for many patients relief of symptoms is only modest, leaving patients with a significantly reduced quality of life. However, palliative care is less frequent for these patients than for patients with advanced lung cancer [50] and most COPD patients receive inadequate palliative care [51]. This was emphasized in the SUPPORT study (Study to Understand Prognoses and Preferences for Outcomes and Risks of Treatment) [52] where patients with severe COPD and with advanced lung cancer were compared. The results of this landmark study demonstrated that advanced COPD patients had significant physical and psychological distress but their need for adequate symptom control, and communication with health professionals regarding the prognosis, treatment goals, and further care plan were not adequately addressed. Contrary to this undersupply and underlining the importance of adequate palliative care in COPD, in a hospicelike approach, advanced COPD patients reported significantly better outcomes on self-management of illness, greater vitality, lower symptom distress, better physical functioning, and self-rated health than did randomized controls [53]. Patients with advanced COPD have a high burden of disabling physical symptoms combined with frequent comorbidities, psychological distress, and social isolation. Although anxiety and depression are common and frequently found already in earlier stages in COPD, they are not well recognized and are undertreated [54].

The main distressing symptom experienced by these patients is dyspnea. Besides conventional medical management, complementary palliative intended options for 
the management of refractory dyspnea in COPD include oxygen, opioids, psychotropic drugs, inhaled furosemide, heliox, rehabilitation, nutrition, psychosocial support, breathing techniques, and breathlessness clinics [55]. Although noninvasive ventilation is mainly used with a lifeprolonging intent, also dying COPD patients with severe dyspnea might obtain symptom relief with the use of noninvasive ventilation [56]. Lung volume reduction in severe emphysema can also be given consideration as a palliative approach to improve lung function, exercise tolerance, and symptoms [57-59].

\section{Idiopathic Interstitial Pneumonias}

Idiopathic interstitial pneumonias are interstitial lung diseases of unknown etiology sharing several clinical and radiologic features. They are distinguished primarily by the histopathologic patterns on lung biopsy and a specific radiologic appearance and are classified into 6 histologic subtypes with varying degrees of inflammation and fibrosis. Main symptoms are moderate to severe dyspnea and cough. Moreover, functional exercise tolerance and quality of life have been shown to be significantly affected in patients with lung fibrosis. Diagnosis is based on history, physical examination, imaging, pulmonary function tests, and in part lung biopsy. Treatment varies by subtype but typically involves corticosteroids, cytotoxic drugs, or both. Prognosis varies by subtype and ranges from excellent to nearly always fatal $[60,61]$. Therefore, in patients with idiopathic lung fibrosis there is a clear indication to initiate palliative care in an early phase of the disease. The symptom burden is usually high in patients with lung fibrosis and frequently impairs their quality of life seriously. If treatment of the underlying disease is impossible, refractory, or causes essential side effects, symptomatic treatment of the main symptoms dyspnea, cough, anxiety, and depression is indicated as discussed in previous sections.

The natural history of most idiopathic interstitial pneumonias is characterized by a progressive decline in lung function, although the course of the disease may be highly variable among individual patients. In fact, the mean survival for IPF patients is 2-4 years, and 5-year survival rates are only $23-50 \%$ [60]. The main cause of death is respiratory failure [62]. Respiratory failure may have potentially reversible causes like pulmonary infection or pulmonary embolism but is most frequently caused by disease progression. The outcome with mechanical ventilation for acute respiratory failure patients in end-stage IPF is very poor, with reports from a systematic review of hospital mortality of $87 \%$ [63], but may be a reasonable choice in a minority of cases $[60,64]$. Noninvasive positive pressure ventilation may be appropriate in some patients, providing relief from dyspnea and avoiding mechanical ventilation.

\section{Bronchiectasis}

Bronchiectasis is a disease state defined by localized, irreversible dilation of part of the bronchial tree caused by destruction of the muscle and elastic tissue. It is classified as an obstructive lung disease, along with emphysema, bronchitis, asthma, and cystic fibrosis. Involved bronchi are dilated, inflamed, and easily collapsible, resulting in airflow obstruction and impaired clearance of secretions. Bronchiectasis is associated with a wide range of disorders, but it usually results from necrotizing bacterial infections, such as infections caused by the Staphylococcus or Klebsiella species or Bordetella pertussis [65].

One of the major determinants of well-being and longevity is the rate of fall of lung function. It is therefore essential that the aims of therapy be focused on the maintenance of good lung function and its determinant factors [66]. As bronchiectasis progresses toward respiratory failure and end-organ complications, much can be done to support the patients' needs and improve symptom control. It is as important to be aware of these factors in the management of patients as it is to optimize lung function, body mass index (BMI), and other quantifiable indices during more stable phases of the disease [67].

Although a flare of airway infection may be caused by a viral upper respiratory tract infection or infection with atypical organisms, the local bacterial population in the airways is quick to take advantage of any reduction in host defense associated with such events. Knowledge of the dominant organism and previous responsiveness to therapy is therefore important for treatment. For most patients with $P$. aeruginosa infection, a switch to oral ciprofloxacin and the addition of or increase in the dose of inhaled tobramycin may avoid hospital admission. Oral ciprofloxacin may be as effective as intravenous treatment [68]. Precipitating factors including viral infection, gastroesophageal reflux, and psychological stress should be identified and managed appropriately.

Even though $\mathrm{FEV}_{1}$ is considered the best single predictor of survival in bronchiectasis, an FEV of less than $30 \%$ predicted associated with hypoxemia or hypercapnia limits survival to $50 \%$ at 2 years [48]. Long-term oxygen therapy has been shown to improve survival in 
COPD, and this treatment has now been extended to bronchiectasis. If chronic hypercapnia occurs, noninvasive positive pressure ventilation may transiently normalize blood gases, but long-term benefits have not been proven.

\section{Financial Disclosure and Conflicts of Interest}

Nothing to declare.

\section{References}

1 Lanken PN, Terry PB, DeLisser HM, Fahry BF, Hansen-Flaschen J, Heffner JE, Levy M, Mularski RA, Osborne ML, Prendergast TJ, Rocker G, Sibbald WJ, Wilfond B, Yankaskas JR: An official American Thoracic Society clinical policy statement: palliative care for patients with respiratory diseases and critical illnesses. Am J Respir Crit Care Med 2008;177:912-927.

-2 Post SG, Puchalski CM, Larson DB: Physicians and patient spirituality: professional boundaries, competency, and ethics. Ann Intern Med 2000;132:578-583.

3 Wright GW, Branscomb BV: Origin of the sensations of dyspnea. Trans Am Clin Climatol Assoc 1966:116-125.

4 Wasserman K, Cassaburi R: Dyspnea: physiological and pathophysiological mechanisms. Annu Rev Med 1988;39:503-515.

5 Simon PM, Schwartzstein RM, Weiss JW, LaHive K, Fencl V, Teghtsoonian M, Weinberger SE: Distinguishable sensations of breathlessness in normal volunteers. Am Rev Respir Dis 1989;140:1021-1027.

-6 Mahler DA, Harver A, Lentine T, Scott JA, Beck K, Schwartzstein RM: Descriptors of breathlessness in cardiorespiratory diseases. Am J Respir Crit Care Med 1996;154:13571363.

7 Dyspnea: mechanisms, assessment, and management: a consensus statement. American Thoracic Society Am J Respir Crit Care Med 1999;159:321-340.

8 Booth S: Management of dyspnoea - oxygen and airflow; in Ahmedzai SH, Muers MF (eds): Supportive Care in Respiratory Disease. Oxford, Oxford University Press, 2005, vol 1, pp 165-188.

-9 Cowcher K, Hanks GW: Long-term management of respiratory symptoms in advanced cancer. J Pain Symptom Manage 1990;5:320 330.

10 Davis C: Management of dyspnoea - drug therapy; in Ahmedzai SH, Muers MF (eds): Supportive Care in Respiratory Disease. Oxford, Oxford University Press, 2005, vol 1, pp 147-164.

11 American Thoracic Society: Statement on home care for patients with respiratory disorders. Am J Respir Crit Care Med 2005; 171: 1443-1464.
12 Jones PW, Quirk FH, Baveystock CM, Littlejohns P: A self-complete measure of health status for chronic airflow limitation: the St. George's Respiratory Questionnaire. Am Rev Respir Dis 1992;145:1321-1327.

13 Twycross R: Symptom Management in Advanced Cancer. Abingdon, Radcliffe Medical Press, 1997.

14 Barnes PJ: New therapies for chronic obstructive pulmonary disease. Thorax 1993; 53:437-447.

15 Walsh, TD: Opiates and respiratory function in advanced cancer. Recent Results Cancer Res 1984;89:115-117.

16 Graff GR, Stark JM, Grueber R: Nebulized fentanyl for palliation of dyspnea in a cystic fibrosis patient. Respiration 2004;71:646-649.

17 Goldsobel AB, Chipps BE: Cough in the pediatric population. J Pediatr 2010;156:352-358.

18 Chung KF, Pavord ID: Prevalence, pathogenesis, and causes of chronic cough. Lancet 2008;371:1364-1374.

19 Myers J: Physiology and pathophysiology of cough; in Ahmedzai SH, Muers MF (eds): Supportive Care in Respiratory Disease. Oxford, Oxford University Press, 2005, vol 1,pp 341-364.

20 Kardos P, Berck H, Fuchs KH, Gillissen A, Klimek L, Morr H, Pfeiffer-Kascha D, Schultze-Werninghaus G, Sitter H, Voshaar T, Worth H: Guidelines of the German Respiratory Society for diagnosis and treatment of adults suffering from acute or chronic cough. Pneumologie 2010;64:336-373.

21 Morice AH, McGarvey L, Pavord I: Recommendations for the management of cough in adults. Thorax 2006;61(suppl I):i1-i24.

22 Morice AH: The diagnosis and management of chronic cough. Eur Respir J 2004;24:481492.

23 Dicpinigaitis PV, Tso R: Prevalence of depressive symptoms in patients with chronic cough. Proc Am Thorac Soc 2005;2:A520.

24 Key A, Holt K, Hamilton A, Smith J, Earis J: Objective cough frequency in idiopathic pulmonary fibrosis. Cough 2010;6:4.

25 Wee B: Chronic cough. Curr Opin Support Palliat Care 2008;2:105-109.

26 Chung KF: Currently available cough suppressants for chronic cough. Lung 2008; 186(suppl 1):S82-S87.

27 Sevelius H, McCoy JF, Colmore JP: Dose response to codeine in patients with chronic cough. Clin Pharmacol Ther 1971;12:449455 .
28 Aversa C, Cazzola M, Clini V, Dal Negro R, Maiorano V, Tana F, Allegra L: Clinical trial of the efficacy and safety of moguisteine in patients with cough associated with chronic respiratory diseases. Drugs Exp Clin Res 1993;19:273-279.

29 Allegra L, Bossi R: Clinical trials with the new antitussive levodropropizine in adult bronchitic patients. Arzneimittelforschung 1988;38:1163-1166.

30 Smith J, Owen E, Earis J, Woodcock A: Effect of codeine on objective measurement of cough in chronic obstructive pulmonary disease. J Allergy Clin Immunol 2006;117:831-835.

- 31 Morice AH, Menon MS, Mulrennan SA, Everett CF, Wright C, Jackson J, Thompson R: Opiate therapy in chronic cough. Am J Respir Crit Care Med 2007;175:312-315.

32 Hope-Gill BD, Hilldrup S, Davies C, Newton RP, Harrison NK: A study of the cough reflex in idiopathic pulmonary fibrosis. Am J Respir Crit Care Med 2003;168:995-1002.

33 Horton MR, Danoff SK, Lechtzin N: Thalidomide inhibits the intractable cough of idiopathic pulmonary fibrosis. Thorax 2008; 63: 749.

34 Lingerfelt BM, Swainey CW, Smith TJ, Coyne PJ: Nebulized lidocaine for intractable cough near the end of life. J Support Oncol 2007;5:301-302.

35 Molassiotis A, Smith JA, Bennett MI, Blackhall F, Taylor D, Zavery B, Harle A, Booton R, Rankin EM, Lloyd-Williams M, Morice $\mathrm{AH}$ : Clinical expert guidelines for the management of cough in lung cancer: report of a UK task group on cough. Cough 2010;6:9.

36 Doherty MJ, Mister R, Pearson MG, Calverley PM: Capsaicin responsiveness and cough in asthma and chronic obstructive pulmonary disease. Thorax 2000;55:643-649.

-37 Torrego A, Haque RA, Nguyen LT, Hew M, Carr DH, Wilson R, Chung KF: Capsaicin cough sensitivity in bronchiectasis. Thorax 2006;61:706-709.

38 Morice AH: The therapy of expectoration; in Ahmedzai SH, Muers MF (ed): Supportive Care in Respiratory Disease. Oxford, Oxford University Press, 2005, vol 1, pp 381-390.

39 Fuchs HJ, Borowitz DS, Christiansen DH, Morris EM, Nash ML, Ramsey BW, Rosenstein BJ, Smith AL, Wohl ME: Effect of aerosolized recombinant human DNase on exacerbations of respiratory symptoms and on pulmonary function in patients with cystic fibrosis. N Engl J Med 1994;331:637-642. 
40 Eng PA, Morton J, Douglass JA: Short-term efficacy of ultrasonically nebulized hypertonic saline in cystic fibrosis. Pediatr Pulmonol 1996;21:77-83.

41 Karwa M, Chandra A, Mirza A: Palliative care and chronic obstructive lung disease; in Blank A, O’Mahony S, Selwyn A (eds): Choices in Palliative Care. Springer, 2007, vol 1, pp 99-123.

42 Schoni MH: Autogenic drainage - a modern approach to physiotherapy in cystic fibrosis. J R Soc Med 1989;82:32-37.

43 Cherny NI, Ahmedzai SH: Pain in association with respiratory conditions: assessment in research and clinical practive; in Ahmedzai SH, Muers MF (eds): Supportive Care in Respiratory Disease. Oxford, Oxford University Press, 2005, vol 1, pp 427438.

44 Ripamonti C, Fulfaro F: Mechanisms of pain associated with respiratory disease; in Ahmedzai SH, Muers MF (eds): Supportive Care in Respiratory Disease. Oxford, Oxford University Press, 2005, vol 1, pp 413-426.

45 Sobanski P, Zylicz Z: Treating severe pain in advanced lung disease; in Ahmedzai $\mathrm{SH}$, Muers MF (eds): Supportive Care in Respiratory Disease. Oxford, Oxford University Press, 2005, vol 1, pp 439-452.

46 World Health Organization: WHO's pain ladder. 2011. http://www.who.int/cancer/ palliative/painladder/en/ (accessed July 2, 2011).

-47 Krajnik M, Finlay LG, Zylicz Z: Opioids affect inflammation and the immune system. Pain Rev 1998;5:147-154.

48 Barker FA: Bronchiectasis. N Engl J Med 2002, 346:1383-1393

-49 Gompelmann D, Eberhardt R, Herth FJF: Advanced malignant lung disease: what the specialist can offer. Respiration 2011;82:111123.

$50 \mathrm{Au}$ DH, Udris EM, Fihn SD, McDonnell MB, Curtis JR: Differences in health care utilization at the end of life among patients with chronic obstructive pulmonary disease and patients with lung cancer. Arch Intern Med 2006;166:326-331
51 Curtis JR: Palliative and end-of-life care for patients with severe COPD. Eur Respir J 2008;32:796-803.

52 A controlled trial to improve care for seriously ill hospitalized patients: the study to understand prognoses and preferences for outcomes and risks of treatments (SUPPORT). The SUPPORT Principal Investigators. JAMA 1995;274:1591-1598.

53 Aiken LS, Butner J, Lckhart CA, Volk-Craft BE, Hamilton G, Williams FG. Outcome evaluation of a randomized trial of the PhoenixCare intervention: program of case management and coordinated care for the seriously chronically ill. J Palliat Med 2006;9: 111-125.

54 van Ede L, Yzermans CJ, Brouwer HJ: Prevalence of depression in patients with chronic obstructive pulmonary disease: a systematic review. Thorax 1999;54:688-692.

55 Uronis HE, Currow DC, Abernethy AP: Palliative management of refractory dyspnea in COPD. Int J COPD 2006;1:289-304.

-56 Shee CD, Green M: Non-invasive ventilation and palliation: experience in a district general hospital and a review. Palliat Med 2003; 17:21-26.

57 Sciurba FC, Ernst A, Herth FJ, Strange C, Criner GJ, Marquette $\mathrm{CH}$, Kovitz KL, Chiacchierini RP, Goldin J, McLennan G: A randomized study of endobronchial valves for advanced emphysema. N Engl J Med. 2010;363:1233-1244.

58 Herth FJ, Gompelmann D, Stanzel F, Bonnet R, Behr J, Schmidt B, Magnussen H, Ernst A, Eberhardt R: Treatment of advanced emphysema with emphysematous lung sealant. Respiration 2011;82:36-45.

59 Palange P: Management of COPD: surgical options. Respiration 2001;68:335-342.
60 Raghu G, Collard HR, Egan JJ, Martinez FJ, Behr J, Brown KK, Colby TV, Cordier JF, Flaherty KR, Lasky JA, Lynch DA, Ryu JH, Swigris JJ, Wells AU, Ancochea J, Bouros D, Carvalho C, Costabel U, Ebina M, Hansell DM, Johkoh T, Kim DS, King TE Jr, Kondoh Y, Myers J, Müller NL, Nicholson AG, Richeldi L, Selman M, Dudden RF, Griss BS, Protzko SL, Schünemann HJ, ATS/ERS/JRS/ ALAT Committee on Idiopathic Pulmonary Fibrosis: An official ATS/ERS/JRS/ALAT statement - idiopathic pulmonary fibrosis: evidence-based guidelines for diagnosis and management. Am J Respir Crit Care Med 2011;183:788-824.

61 Spruit MA, Janssen DJ, Franssen FM, Wouters FM: Rehabilitation and palliative care in lung fibrosis. Respirology 2009;14:781-787.

62 Panos RJ, Mortenson RL, Niccoli SA, King TE Jr: Clinical deterioration in patients with idiopathic pulmonary fibrosis: causes and assessment. Am J Med 1990;88:396-404.

63 Mallick S: Outcome of patients with idiopathic pulmonary fibrosis (IPF) ventilated in intensive care unit. Respir Med 2008;102: 1355-1359.

64 Mollica C, Paone G, Conti V, Ceccarelli D, Schmid G, Mattia P, Perrone N, Petroianni A, Sebastiani A, Cecchini L, Orsetti R, Terzano C: Mechanical ventilation in patients with end-stage idiopathic pulmonary fibrosis. Respiration 2010;79:209-215.

65 Hassan I: Bronchiectasis. eMedicine Specialties Encyclopedia. Gibraltar, WebMD (accessed June 22, 2007).

66 Wilson JW, Kotsimbos AT: The management of cystic fibrosis; in Ahmedzai SH, Muers MF (eds): Supportive Care in Respiratory Disease. Oxford, Oxford University Press 2005;1:391-410.

67 Shoemark A, Ozerovitch L, Wilson R: Aetiology in adult patients with bronchiectasis. Resp Med 2007;101:1163-1170.

- 68 Hodson ME, Roberts CM, Butland RJ, Smith MJ, Batten JC: Oral ciprofloxacin compared with conventional intravenous treatment for Pseudomonas aeruginosa infection in adults with cystic fibrosis. Lancet 1987;31:235-237. 